\title{
PfP, EAPC, and the PfP Consortium: Key Elements of the Euro-Atlantic Security Community
}

\author{
Jean-Jacques de Dardel *
}

\section{PfP: An Idea Bigger Than Its Size}

To many in the wider public, the Partnership for Peace, or PfP, is still more reminiscent of comic strip onomatopoeia than of a serious institution. Yet for anyone accustomed to military and international abbreviations, those three letters and their French equivalent, PPP, are worthy of an AAA rating. Since its inception about fifteen years ago, the Partnership for Peace has developed into a genuine success story, both in the quality and the quantity of its achievements. Although the necessities imposed by the sudden reshaping of the heretofore bipolar world with the end of the Cold War no doubt gave the new partnership a strong head start, it does seem that it quickly not only met all expectations, but even surpassed them. Indeed, the Partnership was widely seen, at first, as a transitional arrangement meant to enable a reorientation of many national security policies to allow nations time to adjust to the prerequisites of NATO membership. Yet the far-reaching concept of the Partnership for Peace, its à la carte principles, and its functional workings have not only allowed it to offer more than a mere stepping stone towards membership in the Atlantic Alliance, they have also ensured that the wider Partnership developed a life and a purpose of its own. In addition, some of its offshoots, such as the Consortium of Defense Academies and Security Studies Institutes, thrived on the spirit of the Partnership in a groundbreaking manner. Why all of this was able to happen is the first question to which we should turn our attention.

\section{The Partnership's Main Aim}

Upon completion of the necessary preparatory work, NATO launched the PfP in January 1994 and declared that its aim was to go "beyond dialogue and cooperation to forge a real partnership - a Partnership for Peace. [...] The Partnership will expand and intensify political and military cooperation throughout Europe, increase stability, diminish threats to peace, and build strengthened relationships by promoting the spirit of practical cooperation and commitment to democratic principles that underpin our Alliance." ${ }^{1}$ Key elements in the invitation were its extension to all non-allied countries that were members of the Conference on Security and Cooperation in Europe (CSCE), and the practical nature of the offer to cooperate on the basis of common values.

Dr. Jean-Jacques de Dardel is Switzerland's Ambassador to NATO.

1 NATO Ministerial Communiqué M-1(94)2, "Partnership for Peace: Invitation issued by the Heads of State and Government participating in the Meeting of the North Atlantic Council“ (10 January 1994). 
On its face, that official description of the purpose of PfP can be said to have been both precise and prescient. But that foresight did not come immediately. It came rather as a solution to a dilemma that NATO was facing at the time as it pondered over its enlargement and its future. Indeed, in response to the demise of the Soviet empire and the scuttling of the Warsaw Pact, the Atlantic Alliance laid down in 1991 the first institutional basis for a new security structure by creating the North Atlantic Cooperation Council (NACC), ${ }^{2}$ designed "to promote both mutual reassurance and increasingly close ties." 3 The pressing issues emerging at the end of the Cold War called for immediate (but transitional) arrangements, hence the limited aim and the transience implied by the mere reassurance and the characterization of the growing new ties between former adversaries. The methods that were to give substance to the Council were mainly the exchange of regular diplomatic liaison in fields of interest to the Alliance and its new potential partners, as well as the intensification of military contacts at various levels. Soon, however, the limitations of the NACC came to the fore.

While the NACC was simply designed to bridge a gap and offer new paths to possible new fields of cooperation, it also seemed too modest for the ambitions of some members. It thus appeared to underline the reservations of certain parties and act as an impediment to, rather than an accelerator of, the rapid development of lasting bonds. Indeed, as a purely multilateral forum for dialogue that was not meant to facilitate selfdifferentiation nor take full account of national idiosyncrasies, and limited as it was in its opening solely to the regions of the former Warsaw Pact, the NACC was insufficient to respond to the needs of the 1990s — an era that was further disrupted by the dissolution of Yugoslavia. Some European countries were definitely looking for more. The NACC, notwithstanding its shortcomings, was instrumental in shaping the wider Partnership for Peace, as it revealed the larger needs of the hour and led the Alliance to conceive the Partnership for Peace as we know it.

\section{PfP's Inner Wisdom}

If PfP was from the outset more than a gimmick, it was because it embodied a certain conceptual wisdom that allowed it to thrive. First of all, by establishing a wide and open-ended institution, NATO increased almost overnight the number of its partners. This opening did not only enable an eastward expansion; it also solidified the European security structures, inasmuch as it progressively engaged Western European neutral and non-allied countries. ${ }^{4}$ The latter thereafter initiated or became important contributors to a large number of PfP projects in favor of defense and broader security

2 The NACC initially comprised the sixteen Allied nations and nine Central and Eastern European countries. By June 1992, it included all members of the Commonwealth of Independent States, as well as Albania and Georgia.

3 NATO Ministerial Communiqué, "Partnership with Countries of Central and Eastern Europe” (6-7 June 1991).

4 Finland and Sweden joined the PfP in 1994, Austria in 1995, Switzerland in 1996, and Ireland in 1999. 
sector reform in transition countries, thus contributing significantly to the stabilization and development of sizeable parts of the eastern half of the continent.

Second, PfP also allowed NATO to address some specific concerns of former Warsaw Pact members that were looking for closer ties to the West and required more practical, tailor-made cooperation. Beyond what NACC was able to provide, PfP usefully stepped up the level of rapprochement, inasmuch as "active participation in the Partnership for Peace [was to] play an important role in the evolutionary process of the expansion of NATO” at a time when it seemed necessary to postpone decisions on full accession to NATO by new members until after the presidential elections of 1996 in the United States and in Russia. ${ }^{5}$

Third, NATO gave itself the appropriate tools to respond to a set of new challenges. It is true that the risk that a situation would occur that required an Article V operation seemed rather remote at the time, but a wide range of security risks were nevertheless present in the region, and at least some of them warranted concerted action beyond the then sixteen-member North Atlantic Alliance. And so, through its very practical aspects, PfP quickly strengthened the Alliance's outreach capacity and its relevance to all situations that would have involved its new partners.

\section{PfP's Outer Wisdom}

Whereas NATO crafted the Partnership as a tool to help promote its own interests, it also met other countries' aspirations — or neutralized some fears. Indeed, it extended a hand and opened doors not only to former Soviet bloc and newly independent countries, but it also brought in the Russian Federation itself, thus establishing a new operational avenue for cooperation (or at least a functional channel for multilayered dialogue). This willingness on the part of Moscow to engage in such a new form of cooperation exemplifies another virtue of the Partnership for Peace: because it was well thought through and offered the right mix of general openness and of particular attention to each partner's needs, it was also met by a remarkable openness of mind on the part of the new partner nations. In other words, NATO's own wisdom was met with commendable wisdom from its partners too. Partners were quick to accept the outstretched hand and to subscribe to new ideas that often entailed difficulties and hard work, and sometimes carried political risks on the home front. That was not self-evident for a number of partners, who had to accept a new game, which was being played according to new rules. Furthermore, the Partnership for Peace doubled other efforts to redraw and reinforce the common European security architecture, most notably at the CSCE. ${ }^{6}$ Striking a balance between the various fora was a delicate exercise, and it can be said that the rapid development of PfP is also to be attributed to those active and imaginative Partner nations that were willing to take some risks for the sake of what the Partnership purported to achieve.

5 Partnership invitation issued at the ministerial meeting of the NAC, Brussels, 10-11 January1994.

6 At a time when the CSCE was transformed into the OSCE, in 1994. 
Thus PfP grew quickly and calmed any fears that it may have been a mere flight forward on the part of NATO, the opening of a Pandora's Box, or even the beginning of the unraveling of the Alliance's cohesion. To the contrary, it brought the Alliance a new dimension, a new functionality - indeed, it offered a new strength and new capabilities. It added real incremental value to transatlantic security, and carried hardly any unwarranted costs.

\section{The Recipe for PfP's Success}

Wisdom by itself is not enough to ensure the success of a wide-ranging endeavor. However well meant, all new concepts need to be translated into working mechanisms that withstand the passage of time, the wearing of novelty, the emergence of new conflicting or competing ideas or needs. How, then, was PfP able to work so well? Because of one dominant characteristic, which is in fact rather rare in the realm of highlevel intergovernmental relations: from the start, and however lofty the ideals and values at the core of the Partnership, what was privileged was a pragmatic, operational, non-ideological, and no-nonsense, down-to-earth approach.

Of course, such an approach is not the only recipe for success, and many an international body owes its strength to a top-down process of development and a robustly hierarchical structure, where the will of the highest-level decision makers, constantly expressed in the political arena, trickles down to the more technical strata. However, the Partnership's pragmatism helped save time and effort among widely different partners with heterogeneous needs and interests. It conveyed immediate tangible results, thus convincing national militaries and other establishments of its worth. And it allowed for the flexibility needed to prompt a dynamic development of various new forms of cooperation.

Some of its key features are worth mentioning. PfP owes its flexibility in large part to the fact that it is based on a political declaration, not a full-fledged treaty entailing a set of obligations, some of which would have been difficult to subscribe to for some of its members. Secondly, PfP was focused from the start on highly substantive and central issues that were crucial to the reorientation of many a newly independent (or fully independent) country: strengthening the democratic control of the armed forces; enhancing transparency in military procurement and in the wider defense sector; and enhancing capability in crisis response management, peace support operations, and civil emergency planning, through cooperative and (where applicable) common planning, training, and education. Finally, PfP established interoperability as a long-term goal for all members, which made it relevant for all military and security establishments. ${ }^{\text {? }}$

In fact, that pragmatism was the single most effective trigger factor that enabled a country such as Switzerland to participate early on in PfP. Indeed, for a permanently neutral state which has never been in an alliance in the last several centuries, and which has no intention to change this fundamental characteristic of its security policy, joining forces with no less than NATO and former Soviet bloc countries meant a sea change

For a full list of the Partnership’s goals, see "Partnership for Peace: Framework Document," annex to the NATO Ministerial Communiqué M-1(94)2, 10 January 1994. 
had taken place. Moving from a staunch reliance on its own forces to a new concept of "security through cooperation" meant a complete change of paradigm, even though that change did not imply abandoning neutrality. ${ }^{8}$ It can be argued that switching alliances, however momentous the change may be in the case of a political turnaround as profound as the one that occurred with the fall of the Berlin Wall, means no more than a divorce and a remarriage: the essentials of married life are known. In that case, in the security field, the instruments of the trade remain the same: cooperation, coordination, temporary or long term subordination, and consultation are simply pursued, albeit with different partners. But for Switzerland, this shift from a state of total self-reliance to habits of cooperation and cooperative attitudes meant a complete alteration of mental referents, a foray into worldly promiscuity away from monastic austerity. Had that institutional move been allowed only within a rigid framework of constraints and obligations, that evolution would simply not have been deemed possible in Switzerland-just as it would most likely have been rather controversial in other neutral countries.

Not surprisingly, some members of the Swiss Federal Assembly (Parliament) questioned at the time the compatibility of PfP with Swiss neutrality. ${ }^{9} \mathrm{PfP}$ was seen by some as a step towards full NATO membership. Yet PfP's open and non-constraining structures and philosophy were well taken by most. The Swiss Federal Council (government) and the majority of Parliament sensed or understood the potential of PfP within the framework of Swiss neutrality. As the head of the Swiss Defense Department, Federal Councilor Adolf Ogi-the father of Switzerland's accession to PfPsaid two years later at the first annual conference of the Consortium of Defense Academies and Security Studies Institutes: "neutrality does not preclude a country to participate actively in the search for peace and stability through international cooperation." 10

What was most appreciated in Switzerland were the principles of self-differentiation and self-determination, as well as the non-contractual form of the process, which guaranteed to Switzerland total control over not only the scope and scale of Swiss participation, but over the ability to keep in tune with Swiss public opinion. Such à la carte principles ensured that Swiss conditio sine qua non were duly taken into account, just as other prevailing attitudes and characteristics in other countries could also be fully factored in. Thus, in 1996-the year in which it presided over the OSCE-Switzerland rose to the new security challenges which had been made starkly apparent by

8 Due to its mixed experience with the League of Nations, of which Switzerland was an active member before the world's security structures collapsed in the face of mounting totalitarianism, Switzerland remained skeptical about the concepts of collective security.

9 Autumn session of the Swiss National Council, eleventh meeting, 1 October 1996.

${ }^{10}$ Opening address of the Third International Security Forum and First Conference of the PfP Consortium of Defense Academies and Security Studies Institutes, "Networking the Security Community in the Information Age," 19-21 October 1998, Zurich, Switzerland. Published in Hans W. Odenthal, Kurt R. Spillman, and Andreas Wenger, eds., Conference Report (Rome: NATO Defense College Monograph Series, Summer 1999). 
the wars in former Yugoslavia, and accepted NATO's offer to join the Partnership for Peace. $^{11}$

This major step forward was followed by substantive work on a new concept for Swiss security policy, which materialized in 2000 in the form of the "Report of the Federal Council to the Federal Assembly on the Security Policy of Switzerland," which remains the basis of Swiss security policy to this day. Through this process, PfP has had a major impact on Switzerland's policies. It has also provided proof that tailormade solutions to cooperation-based on individual nations' needs and circumstances - can encourage progress much more successfully (and more quickly) than political or moral pressures, which may well have an adverse effect.

\section{EAPC: The Essential Framework}

However well PfP developed and was put into practice, however efficient it has become since it was based on an operational approach, the Partnership would most probably not have been sustainable in the long run had it not been for the constant and renewed political support it received. Practical cooperation needed a political complement if it wanted to reach lasting objectives. The NACC structure was limited, as we have seen, and simply expanding its membership could have been seen as merely further experimenting under an unproved model. There definitely appeared to be a need for a new overarching political framework to allow PfP to fully develop its potential and to guarantee its continued functioning, despite the growing complexity, commitments, and even investments it demanded. Thus, the NATO-led peacekeeping operation in Bosnia-Herzegovina, which started in December 1995 and featured meaningful non-NATO participation, triggered the creation of the EAPC, since that crisis necessitated full and close high-level political involvement and synchronization among all participating nations. $^{12}$

The Euro-Atlantic Partnership Council was established in 1997. The goal, as Robert Simmons put it, was to develop a forum for political consultation among all partners that would be aligned with the Partnership for Peace's modes of more practical cooperation. ${ }^{13}$ Its objective was spelled out clearly in its basic document:

The Euro-Atlantic Partnership Council, as the successor to NACC, will provide the overarching framework for consultations among its members on a broad range of political and security-related issues, as part of a process that will develop through practice. PfP in its enhanced form will be a clearly identifiable element within this flexible framework. Its basic elements will remain valid. The Euro-Atlantic Partnership Council will build upon the existing framework of NATO's outreach activities, pre-

11 The two-year delay since the creation of PfP was due to the 1994 referendum in Switzerland that rejected the creation of a Swiss "blue helmet" contingent for the United Nations.

12 It was also a catalyst for PfP, since when they decided to launch the EAPC, the ministers meeting in Sintra in late May 1997 also decided to enhance the Partnership.

13 Robert Simmons, “Ten Years of the Euro-Atlantic Partnership Council: A Personal Reflection,” NATO Review (Summer 2007), available at www.nato.int/docu/review/2007/issue2/ english/art5.html. 
serving their advantages to promote cooperation in a transparent way. The expanded political dimension of consultation and cooperation which the Council will offer will allow Partners, if they wish, to develop a direct political relationship individually or in smaller groups with the Alliance. In addition, the Council will provide the framework to afford Partner countries, to the maximum extent possible, increased decisionmaking opportunities relating to activities in which they participate. ${ }^{14}$

The EAPC was generally understood to be an essential new body at that time, for a number of reasons. First, it created a political counter-weight that extended the practical demands of operative cooperation, allowing a validation of the Partnership at the political and diplomatic levels - those at which consultations on political and securityrelated issues of common concern must be held if they are to feed any meaningful decision-making process. Second, it guaranteed the involvement in the PfP process of higher levels not only of the governmental sphere, but also of national parliaments. There is no doubt that, over the last decade, the involvement of members of all parliaments of the Euro-Atlantic community has helped assert the value-based nature of the Partnership. The close interactions of parliamentarians meeting at regular intervals within the NATO Parliamentary Assembly has also helped ensure that the security concerns voiced by governments will be promulgated in each national parliament, and that such concerns will be viewed in a broader perspective than that of purely national debates. Third, the EAPC also strengthened the notion of a basic level of equality in the Partnership, irrespective of each country's level of functional integration. This equivalence in standing enables individual member nations to pursue a policy of selfdifferentiation, while also upholding the Partnership's principles of inclusiveness without hampering its commitment to transparency. Since all partners are made to feel that they are on an equal footing at a certain political level, a feeling of cohesion can thrive, despite the material differences between countries and the respective worth of their contribution to international security commitments. The EAPC further provided an immediate response to the need to counterbalance the risk of the appearance of potential new dividing lines across Europe, as the first post-Cold War round of NATO enlargement was approved on the occasion of the EAPC's coming into being. And finally, the flexibility built into the EAPC system echoed the flexibility that was at the heart of the PfP, a virtue that allowed the system to evolve and adapt to a changing environment.

\section{Revalidating the EAPC}

Since its inception in 1997, the EAPC has proved its worth, but this is not necessarily to say that it has aged gracefully throughout its history. As NATO grows, and as more Partner nations are invited to join the Alliance, the EAPC and PfP's roles as steppingstones to NATO membership will tend to subside. The EAPC's attractiveness for those whose main intent is to pursue NATO membership does not subside, but each successful Membership Action Plan (MAP) seems to lower the remaining content of the

14 Basic Document of the Euro-Atlantic Partnership Council, adopted in Sintra, Portugal, 30 May 1997. 
EAPC framework. Undoubtedly, the numbers have changed: whereas Partner nations initially formed a majority clustered around a closely knit Atlantic Alliance minority (in country numbers), the number of NATO nations now outweighs that of the Partners, and that trend continues unabated. In addition, the importance of the issue of full membership in NATO is such that it often distracts from the other virtues of the EAPC/ PfP institution. Consequently, a number of actors and observers have sensed that the EAPC, as a political body, has been waning somewhat in these last few years. Indeed, it is commonly admitted in various circles that the EAPC's importance for NATO has diminished, and that this forum has been losing some of its dynamism as a result, especially at the ministerial level. ${ }^{15}$ This perception is reinforced by the fact that both defense and foreign affairs ministers will meet not twice a year, but only once a year going forward. In addition, the NATO-only summit in Riga in 2006 and the early uncertainties about the convening of an EAPC summit meeting in Bucharest added to the impression of a hollowing of the Council. This reading is also based on a positive assessment of the evolution of the security dialogue, a shift that is attributable in part precisely to the EAPC. As a result of the interaction fostered by the EAPC, a common understanding of security-related issues and threats has broadened, thus apparently lessening the need for a lively political forum to discuss these issues.

Viewed from still another angle, the EAPC/PfP construct has sometimes been narrowed down to an increasingly utilitarian perspective, whereby its main worth is to be counted in terms of capabilities provided in the context of demanding operations on the ground. And indeed, in times of heavy constraints on resources and growing needs for new capabilities in distant theatres of operations, it is perfectly legitimate that the EAPC be looked at through the prism of immediate needs to be met, rather than through the lenses of longer-term interests and purposes.

Yet it can also be argued that there is a risk that the potential supply of new capabilities may dwindle if the discussions at the political level at which they must be committed are not fair and sound. Force generation is not only a military problem, one that simply awaits a political go-ahead in a linear sequence. It is increasingly dependent on overall political—and, indeed, societal—views and approaches to international cooperation and involvement, in which an overall balance of interests and needs plays a functional role. And in cases where force generation as such is not in the cards, a general level of support for an international security effort (along with specific valueadded contributions) will not be forthcoming if those countries that are solicited are not granted the status of full-fledged partners and made to feel that they are listened to.

In this sense, the EAPC's worth and central role has not diminished. Those reasons that prompted the Alliance to establish it in the first place still remain largely valid today (if not for all EAPC members, then at least for a majority). It is thus encouraging to note that the EAPC has been revalidated in the run-up to the Bucharest meeting, and that new commitments to the Partnership have added to the substance of the April 2008

15 Although this is not felt at lower levels, since the work pursued in technical sub-groups such as the PMSC remains quite intensive. 
Summit. And, just as this support for the Partnership was being renewed by all who took the floor, the EAPC "turned fifty" - unquestionably a sign of maturity! ${ }^{16}$

\section{Openness, in More Ways than One}

A lively Partnership, steered by an interactive and participatory Partnership Council, fully corresponds to the interests and needs of a country such as Switzerland. The Swiss authorities thus view the PfP as being as important to its security policy now as it was in the first years of its institutional life. As was mentioned above, the Partnership for Peace had a significant impact on the development of Switzerland's post-Cold War security policy. Switzerland's Ministry of Foreign Affairs developed new structures and teamed up with the Defense Department more closely than it had in the past; general thinking about the country's international security policy evolved at a relatively fast pace; and the military, in the process of transforming the armed forces, let itself be influenced by the outer world in ways unknown in the past. From the start of its membership, Switzerland made good use of the Partnership. In 1997, the year the EAPC was founded, Swiss representatives participated in fifty-six PfP activities. Ten years later, this number had multiplied by four. In addition, Switzerland also participated during this period in NATO-led peace support operations under a UN mandate, contributing armed units and heavy equipment. ${ }^{17}$ The spectrum of activities the country takes part in also widened as the range of security challenges evolved; the fight against terrorism and the protection of critical infrastructure, to name but a few, were added to the more traditional avenues of military cooperation.

This participation, of course, includes a number of activities that are of both direct and incremental benefit to Switzerland, as the country's armed forces, government officials, and security experts gain knowledge, experience, and familiarity with international standards. But this participation is by no means a one-way street. Switzerland has from the start considered itself a net contributor to the transatlantic cooperative framework, and it has endeavored to provide training, expertise, and resources that would benefit the whole. The creation of three centers in Geneva-devoted to security policy training, humanitarian efforts to remove land mines, and the democratic control of the armed forces - no doubt represented a major contribution to PfP, since those centers considerably extended the Partnership's ability to cater to the training needs of countries in transition. ${ }^{18}$

Whereas putting the country's resources at the disposal of Partner countries in need was nothing new for Switzerland, doing so in the security field at these new levels was

16 With the accession of Malta as the fiftieth member state.

17 Most notably in South East Europe, where it is present in Kosovo with a contingent including staff officers and two companies (one infantry and one logistics company), and in Bosnia and Herzegovina with two Liaison and Observation Teams, as well as with helicopter units in both countries.

18 The Geneva Centre for Security Policy (GCSP) was established in 1995, followed by the Geneva International Centre for Humanitarian Demining (GICHD) in 1998, and the Geneva Centre for the Democratic Control of Armed Forces (DCAF) in 2000. 
indeed a novelty. It is yet another positive effect of the Partnership that it has brought new thinking and new understanding of the fields of opportunity that are open for international cooperation between security providers. Thus the EAPC/PfP institution considerably expanded the international peacekeeping capabilities of countries that, like Switzerland, were until then not geared towards sustained military cooperation in the transatlantic sphere.

But this widening of scope, this enlargement of perspectives is itself a two-way street. It can be argued that the intermingling of Allied and Partner nations, particularly at the political and politico-military level, has also helped NATO to factor in other perspectives. Not only do Partner nations contribute certain expertise in a variety of fields that Allied nations and their militaries can also benefit from, they are also a welcome reminder of the wider complexities of the environment in which the Alliance develops its actions. It is through the constant rubbing of elbows of officials of different levels and different ministries, as well as the interactions between civil servants and highranking military personnel, that the EAPC offers all members involved a possibility to test all ideas against a diverse and variegated background (without, it must be stressed, falling into the traps of endless verbal tugs-of-war and posturing).

\section{The Consortium: A Quintessence}

Perhaps nothing better exemplifies the flourishing of modern-day international cooperation in the security field and the incremental value of the kind of pragmatic, tailormade networking afforded by the spirit of EAPC/PfP than the PfP Consortium. The founding fathers of the Consortium are rightly said to be the United States and Germany. Switzerland, however, also considers itself as one of those nations involved in launching the institution. By the time the new concept of the Consortium was endorsed by the EAPC defense ministers at their June 1998 gathering, Switzerland had already prepared the ground for a quick convening of the new body. At that same EAPC ministerial meeting, the Switzerland's then-Minister of Defense Adolf Ogi offered to host the Consortium's first annual conference within the framework of the impending Swiss-sponsored third International Security Forum. This enabled the Consortium to hold its inaugural conference in October 1998 in Zurich, a mere four months after the ministerial endorsement. The Zurich conference in turn enabled the Consortium to clarify the road ahead, establish its internal operational structures, and lay the foundation for future work in the areas of security policy training and research. ${ }^{19}$ Several months later, it was also Federal Councilor Ogi who reported on the successful first

${ }^{19}$ For a detailed report on the first annual conference of the Consortium, see Victor E. Stamey, "The Way Ahead," in Connections: Athena Papers (1998); available at https://consortium.pims.org/events/1st-annual-conference-jan-2006. 
steps of the Consortium at the EAPC ministerial meeting in the defense ministers' session in December $1998 .^{20}$

The Consortium has been able ever since to count on strong Swiss support for and involvement in its work. Two of the previously mentioned institutes, DCAF and GCSP, as well as another noteworthy body located in Switzerland, the International Security Network (ISN), were lead institutions that got heavily involved in the Consortium, supporting it with their resources and know-how. ${ }^{21}$ All three continue to be strongly committed to the Consortium, and two of them run an expert group in their respective field of expertise, namely the Advanced Distributed Learning and Security Sector Reform Working Groups. In addition, a number of Swiss government officials and experts have participated regularly in the work not only of the Steering Committee of the Consortium, but also of various working groups. The comments that will follow, for instance, are based on a number of years of regular personal involvement in one of the working groups devoted to Euro-Atlantic security matters. ${ }^{22}$ I have found my participation in this working group to be a rewarding experience indeed, which allows me to vouch for the excellence of the concept of the Consortium, its utility, and its continued usefulness.

\section{A Mind-opener}

In the course of its ten-year existence, the Consortium has brought together an expanding number of representatives from different countries, Allied and Partner alike, who share an academic interest in security matters. But most importantly, it has done so by crossing the ordinary professional and disciplinary lines that usually distinguish various communities of interest. The Consortium creates direct interactions between academics of various rank, military leaders, and civilian government officials from various ministries. All participants not only exchange information and experience, but also learn to interact, to listen to other views, to think a bit more freely, and depart from the beaten path of their own tried experience and professional biases. All of this takes place on an individual, freethinking basis that would more often than not be difficult or outright impossible in intergovernmental forums. It is true that the process of freeing one's thoughts from familiar disciplinary or professional fetters takes time, and not every Consortium meeting will register novel views and instant cross-fertilization.

20 Status Report Concerning the Partnership for Peace Consortium of Defense Academies and Security Studies Institutes, presented by Federal Councilor Adolf Ogi, Head of the Swiss Department of Defense, Civil Protection, and Sports (Switzerland) at the Meeting of the Euro-Atlantic Partnership Council in the Defense Ministers' Session, Brussels, 18 December 1998.

21 The International Relations and Security Network (ISN) is, as Federal Councilor Ogi noted in 1998, "Switzerland's contribution to a free flow of information and data in the area of security policy. Democracies are built on the free debate of informed citizens.” (Adolf Ogi, Opening address, http://www.isn.ethz.ch/3isf/report/04.htm).

22 Namely the European Security Study Group (ESSG) - then known as the Euro-Atlantic Security Study Group (EASSG) - headed by Major General Alain Faupin (France) and Professor Plamen Pantev (Bulgaria). 
But in the long run, at meeting after meeting of the Consortium working groups, an osmosis does take place, as sparring partners who first came to the table with their own firmly-held opinions and backgrounds learn to listen, instead of only trying to convince others. And it is crucially important that these "others" are not only participants from other countries and regions, but are also individuals drawn from other professional backgrounds (and other generations, too).

Naturally, a number of other international organizations also have set up thinktanks and/or academic bodies that serve as intellectual resources for the organization as a whole. And outstanding think-tanks, university faculties, and consultants are not lacking in the realm of security studies. Within the Partnership itself, centers of excellence such as the George C. Marshall Center in Garmisch-Partenkirchen and the NATO Defense College in Rome (to name but a few ${ }^{23}$ ) are devoted to research, applied studies, training, and even counseling and institution building in some instances. But each such institution is only a single component of the wider network created by the Consortium.

Think-tanks and security studies institutes bring together participants for set periods of time. Training courses and months of internship imply a form of sabbatical leave from ordinary government and military positions. At the other end of the spectrum, one-, two-, or three-day seminars and conferences may serve to bring together groups of government representatives and academics a few times each year. The sporadic exchanges they enable contribute to the store of shared knowledge and foster a certain feeling of belonging to a wider security community. But it is the extended network created by the Consortium, and the form of constant work it implies, that really weaves a close-knit security community. Indeed, participating in a Consortium working group implies more than simply meeting a number of times throughout the year. It entails regular additional work and interaction, as there are papers to be written, presentations prepared, meetings chaired, and reports created. That constant preparatory work implies a deepening of subject matters, giving a truly academic slant to the government participant's approach, and ensuring that the professional academics will have to pay particular attention to the practitioner's points of view.

The breadth and depth of the Consortium's network - and the demands it puts on its participants to adjust to each other's views, even though they are continuously engaged on their home professional fronts-boosts lateral thinking and transverse considerations. These, in turn, help to broaden the understanding of international complexities on which governments are to base their decision-making processes. That is a welcome input at a time when multidisciplinary studies remain far from being the norm, and when specialization and entrenched thought patterns are not sufficiently questioned.

Of course, some may have thought at first - and others might well still think - that the Consortium was and is most useful for the "Eastern" sparring partners. It is this

${ }^{23}$ The Consortium brings together more than 350 organizations from 42 countries of the EuroAtlantic zone. 
group, after all, that had the most catching up to do to come closer to the level of the Alliance-indeed, to that of the democratic West as a whole, after so many years of lopsided ideological indoctrination. But even though there is obviously a solid kernel of truth in this view, it does not give the full picture of what is needed to develop the wider transatlantic security community. In fact, NATO members would do well to remember that they are also constantly engaged in an aggiornamento of their concepts and of their framework references, just as are the other Western partners, who are also in the process of adapting to fast-changing circumstances. For both of these groups of countries, there is something to gain from understanding the thinking, the references and intricacies of those new Partner nations that are going through a momentous systemic transition. In this sense, the Consortium can also bring about new types of crossfertilization, as it favors candid exchanges of views and promotes a better direct understanding of the thought processes current among different blocs and regional groupings.

\section{A Long-term Investment}

The operation of the Consortium is not particularly expensive, since it relies heavily on personal commitment and volunteer work. On the other hand, it does require some resources, and the Consortium could not survive without an assured yearly budget. It is hence very understandable that the major contributors regularly question its workings and ask what value it adds. What is the true return on investments made in the Consortium? Does it only confer benefits on the few, or does it have a sufficient spill-over effect to be a factor of positive influence more generally on other ongoing concerns of the security community, or on specific governments? In other words, is it an essential component of the machinery of international security, or is it merely a nifty gadget? From another (perhaps more cynical) point of view, can the Consortium be seen by some of the players in the Alliance and the EAPC as a tool for achieving better alignment on certain positions? Can it bring a perceptible, quantifiable change in the government policies of some nations? Can it influence decision makers in specific situations? And will it bring about an alignment of views on particular key needs or issues?

To be frank, this is most likely not the case. The Consortium's advantages and promises do not lie in the realm of specific benefits and quantifiable results. As is the case with most mind-building, neuron-stimulating intellectual processes, and most knowledge-enhancing and university-level training, the Consortium serves long-term goals, and generally does not produce immediate returns. There are exceptions to this rule, since some work done on curricula and training methods may well be applied without delay, and some research can flow directly into position papers prepared by Consortium participants. But more generally, the stimulus it provides cannot be quantified as such and readily entered in a balance sheet.

On the other hand, some governments and institutions could well decide to use the networks already created by the Consortium to tap into intellectual resources that are currently available. They could, for instance, turn to specific working groups and suggest study themes, or ask that some issues be discussed and papers produced. Consortium participants would surely not back away from such challenges. 
But the basic value of the Consortium more certainly lies at another level. It enables exchanges of views between and among different groups of participants, without the constraints of negotiations and national positioning, that serve to gradually change perceptions. In such a way, it contributes to the emergence of a wider Euro-Atlantic security community, where both security and community gain a more comprehensive meaning and scope of action. In so doing, it also furthers a better understanding of the virtues of global approaches, and promotes an increased appreciation for comprehensive action plans that rely on very different assets that often lie well beyond those that seem to be on top of most nations' priority lists. Since a global approach is the indispensable, unavoidable path to appropriate, sustainable solutions in complex conflict areas and crisis situations, the Consortium's contribution to lateral thinking and mutual understanding is, by all means, of the essence. 


\section{Bibliography}

Partnership with Countries of Central and Eastern Europe. NATO Ministerial Communiqué (1991).

Simmons, Robert. "Ten Years of the Euro-Atlantic Partnership Council: A Personal Reflection." NATO Review (2007).

Stamey, Victor E.. The Way Ahead., 2000.

Wenger, Andreas, Kurt R. Spillman, and Hans W. Odenthal. Networking the Security Community in the Information Age. Third International Security Forum and First Conference of the PfP Consortium of Defense Academies and Security Studies Institutes, 1999. 